\title{
Terapia Fonoaudiológica Mediada pela Noção de Gêneros do Discurso: (Res)Significando Histórias de Ler e de Escrever
}

\author{
Therapy Mediated by the Speech Genre Notion: \\ (RE)Signifying Histories of ReAding AND Writing
}

Rita Fernandes SIGNOR *

Resumo: O objetivo deste artigo é apresentar parte de uma pesquisa em que analisamos a contribuição da teoria de gêneros do discurso de Bakhtin (2003) para o desenvolvimento de competências em leitura e escrita. Para tanto, elaboramos uma abordagem terapêutica e a aplicamos em uma situação de terapia em grupo. Neste trabalho apresentamos parte da interlocução com um dos sujeitos do grupo, em processo de escrita em um dos gêneros selecionados para o processo terapêutico: o gênero peça de teatro.

Palavras-chave: Leitura e escrita. Terapia fonoaudiológica. Gênero peça de teatro.

Abstract: The aim of this article is presenting part of a research in which we analyze the contribution of Bakhtin's speech genre theory (2003) for the development of competences in reading and writing. To do so, we developed a therapeutic approach and applied it in a group care situation. In the present work, we present the interlocution with one of the subjects who was part of the group, within the process of writing of one of the genres selected for the therapeutic work: the genre theater play.

* Fonoaudióloga do Hospital Infantil Joana de Gusmão. Doutoranda em Linguística pela Universidade Federal de Santa Catarina. Professora voluntária do departamento de Fonoaudiologia da UFSC. Contato: ritasignor@gmail.com 
Key-words: Reading and writing. Speech therapy. The genre theater play.

\section{Introdução}

A grande demanda pelo atendimento fonoaudiológico, por estudantes considerados portadores de supostas dificuldades de leitura e escrita, tem gerado muitas pesquisas na área da linguagem. A maioria desses estudos, no entanto, fundamenta-se em concepções teóricas que ignoram a história do aprendiz e suas relações com o objeto escrito (MASSI, 2004).

Alguns fonoaudiólogos, distantes dos resultados de investigações de vezo sociodiscursivo, que objetivam explicar os processos de apropriação da escrita, limitam-se a confirmar a suspeita da escola ${ }^{1}$ (BERBERIAN; MASSI, 2005). O aluno, por sua vez, duplamente rotulado, na escola e na clínica, acaba assumindo uma postura de distanciamento em relação à escrita.

O mais problemático, sob nosso ponto de vista, é que detectado o "problema", parte-se para o "tratamento" fonoaudiológico. Grande parte das abordagens terapêuticas reflete práticas de leitura e escrita totalmente desprovidas de significação, com enfoque em aspectos formais da língua. Com base nesse paradigma tradicionalista, a dimensão discursiva não é trabalhada, sequer considerada. Julgamos que essa conduta terapêutica alimenta no sujeito os sentimentos de rejeição em relação à linguagem escrita, uma vez que tende a repetir as mesmas experiências vivenciadas na escola ${ }^{2}$.

${ }^{1}$ Em geral, os alunos são encaminhados pelas escolas com suspeita de patologias na área da linguagem escrita, como dislexia, distúrbios de leitura e escrita, dificuldades de aprendizagem, transtorno de déficit de atenção e hiperatividade etc. Ocorre que, na maioria dos casos, constatamos que os sujeitos não portam patologias de fato, e sim instabilidades inerentes ao processo de apropriação da escrita. Salientamos que as manifestações singulares em torno do objeto escrito, quando tomadas como sintomas de possíveis desordens na área da linguagem, tendem a gerar no aprendiz um sentimento de incapacidade linguística.

${ }^{2}$ Durante todo o trabalho, referimo-nos à escola dita "tradicional". 
Desse modo, conforme Berberian e Massi (2005), torna-se imprescindível, no campo da fonoaudiologia, a realização de pesquisas ${ }^{3}$ que tomem a linguagem em sua dimensão constitutiva, histórica e social. Por meio dessa abordagem, o sujeito passa a ser compreendido de outra forma. O processo de apropriação da linguagem é encarado como decorrente de interações sociais mediadas por práticas discursivas. A produção escrita é vista como um processo em que o sujeito, ao usar a linguagem, faz de signos linguísticos significativos, materializados em enunciados proferidos em dada situação social de interação. Embasando nossa prática em uma vertente sócio-histórica, acreditamos que a escrita não representa um código a ser (re)produzido. Assim, consideramos os "erros" ortográficos, principal fonte de encaminhamentos à clínica, como inerentes ao percurso histórico de aprendizagem da linguagem.

Considerando a problemática exposta, propusemos como objetivo de pesquisa (para a dissertação de mestrado) analisar o processo de desenvolvimento de competências de leitura e escrita, por um grupo de alunos encaminhados para atendimento clínico, a partir de uma atuação terapêutica embasada na noção de gêneros do discurso de Bakhtin. Para alcançar o objetivo delineado, elaboramos e desenvolvemos uma proposta terapêutica, que configuramos como um estudo de caso de um atendimento fonoaudiológico em grupo. $\mathrm{O}$ grupo foi composto por cinco adolescentes, entre 11 e 13 anos, que foram encaminhados por suas escolas por apresentarem, segundo parecer dos professores, dificuldades relacionadas à linguagem escrita.

Após conversas iniciais e observação das condições dos participantes da pesquisa, selecionamos um grupo de gêneros do discurso para nortear a nossa ação terapêutica: romance, peça de teatro, cartaz de divulgação e sinopse. Dentre esses, priorizamos a peça de teatro ${ }^{4}$,

${ }^{3}$ A pesquisa apresentada neste artigo representa parte de uma dissertação de mestrado em Linguística, realizada sob orientação da professora Dr. ${ }^{a}$ Rosângela Hammes Rodrigues. O estudo passou pela avaliação e aprovação dos Comitês de Ética da UFSC, sob número 132/2009, e do Comitê do HIJG, sob número 003/2009. Foram assinados os Termos de Consentimento Livre e Esclarecido. ${ }^{4}$ A seleção do gênero peça de teatro como recurso terapêutico teve o intuito de conquistar leitores e produtores de textos por meio da inserção dos sujeitos em uma atividade ligada à esfera da arte. Dessa maneira, distantes das propostas 
sendo os demais decorrentes e necessários ao trabalho centrado em uma proposta de elaboração, publicação e encenação de uma peça. Para a escrita da peça de teatro, partimos da reenunciação de um romance lido em terapia. E para a publicação da peça em site e sua encenação, os sujeitos produziram os gêneros sinopse e cartaz de divulgação.

Os dados foram gerados no período de novembro de 2008 a janeiro de 2010. As sessões foram documentadas com auxílio de um gravador de áudio e de um diário de pesquisa. O atendimento foi realizado em uma sala do ambulatório de leitura e escrita de um hospital infantil. As sessões foram realizadas em grupo, com alguns atendimentos individuais.

Importante considerar que para este artigo, por questões de espaço, apresentaremos parte da trajetória de um dos cinco sujeitos de nossa pesquisa, o sujeito $\mathrm{M}$, e parte do procedimento terapêutico realizado com apenas um dos gêneros trabalhados em terapia, a peça de teatro.

Para dar tratamento analítico-qualitativo aos dados gerados nos episódios dialógicos, resultantes de um estudo longitudinal, tomamos a teoria enunciativo-discursiva explicitada por Bakhtin. Uma abordagem epistemológica sócio-histórica que se oriente pelas concepções bakhtinianas tem, como categoria central, o dialogismo, uma vez que busca atingir os sentidos estabelecidos e promovidos nas situações interacionais.

\section{Apresentação do caso}

M tinha, à época deste estudo, doze anos de idade. Cursava o quinto ano do ensino fundamental (pela terceira vez) em uma escola da rede pública de Florianópolis. Os pais procuraram o serviço de

tradicionalistas realizadas em muitas escolas e clínicas, fundamentados em uma teoria bakhtiniana, pretendíamos dar novos sentidos a uma provável relação negativa dos sujeitos com a linguagem escrita. Pensamos que em meio a contextos significativos de produção de linguagem seja possível ampliar as capacidades discursivas dos aprendizes que nos vêm encaminhados com prédiagnósticos de supostas dificuldades de leitura e escrita. 
fonoaudiologia com a queixa de que $\mathrm{M}$. tinha dificuldades de leitura e escrita e era desmotivado em relação à escola.

O pai de M é garçom e cursou o ensino fundamental completo. A mãe é merendeira em uma escola e também realizava graduação em pedagogia no período noturno. Os pais afirmaram que o desempenho escolar do filho era fraco, pois ele era "muito preguiçoso". Escolheram a escola de $\mathrm{M}$ devido à proximidade da residência em que viviam; no entanto, estavam insatisfeitos com a escola. A mãe, em entrevista inicial, comentou que era constantemente chamada na escola para ouvir reclamações a respeito do desempenho do filho: Eles querem que en ensine em casa, só porque faço pedagogia, mas em casa eu sou mãe e não professora, não posso assumir a responsabilidade que é da escola. Ajudo quando posso, agora, professora dele eu não vou ser não. No discurso de $\mathrm{M}$ foi possível perceber seu distanciamento em relação à escola e às práticas de leitura e escrita desenvolvidas naquele espaço: Não faço nada, revelou, e quando questionamos o porquê de ele não fazer nada [na escola], simplesmente reiterou o dito anteriormente porque não faço nada, sento lá atrás e não faço nada.

A avaliação fonoaudiológica recebida por $M$ esteve pautada em uma concepção constitutiva de linguagem. Seu discurso escrito revelou que o adolescente não possuía distúrbios ou dificuldades de leitura e escrita, uma vez que suas produções textuais cumpriam a função de permitir a construção de sentidos por parte do leitor. A aceitação para terapia, contudo, teve como objetivo ressignificar a queixa apresentada pela escola e família, que traduzida no discurso de $\mathrm{M}$, fez com ele se distanciasse da escola e das "práticas de leitura e escrita" realizadas naquele contexto.

A seguir, um resumo das sessões de terapia relacionadas ao trabalho com o gênero peça de teatro.

${ }^{5}$ Salientamos que, durante todo o período em que M esteve em processo terapêutico, as atividades realizadas na disciplina de Língua Portuguesa em sua escola estiveram longe de práticas sociais de leitura e escrita. Ao contrário, as práticas pedagógicas centraram-se na realização de exercícios gramaticais, distantes das situações concretas de uso da Língua. 


\section{$2 O$ trabalho com o gênero peça de teatro}

$1^{a}$ sessão $^{6}$ : apresentação dos objetivos do trabalho terapêutico e de pesquisa; conversa inicial a respeito do gênero peça de teatro (estudo dos aspectos históricos e da esfera da arte dramática, segundo Berthold (2008); Peixoto (1981)).

* 2a a $4^{a}$ sessões: seleção e leitura do romance (objeto de adaptação): Goosebumps - ele saiu debaixo da pia, de R. L Stine.

$5^{\mathrm{a}}$ a $11^{\mathrm{a}}$ sessões: 1 - leituras e análises de peças de teatro em diferentes modalidades (drama, comédia e tragédia). 2- estudo das propriedades textuais do gênero peça de teatro, como marcação das microrrubricas e macrorrubricas ${ }^{7}$, segundo Cobra (2009). 3- leituras de entrevistas com dramaturgos e elaboração de entrevista para um dramaturgo. 4leituras de trechos das obras Clarissa, de Erico Verísimo, e Crepúsculo, de Stephanie Meyer, para comparação entre gêneros (romance e peça de teatro). Esta atitude objetivou clarificar alguns aspectos relacionados à composição textual do gênero peça de teatro, como, por exemplo, a questão dos tempos verbais (tempo presente - nas indicações de cena - na peça, e tempo pretérito no romance). Para isso, estudamos a função social de cada gênero (interação imediata com o público na peça de teatro e interação distante no romance).

$12^{a}$ a $18^{a}$ sessões: escrita da peça ${ }^{8}$ (parte 1): os vinte e nove

${ }^{6}$ As sessões de terapia tiveram até três horas de duração.

${ }^{7}$ As rubricas são divididas em macrorrubricas e microrrubricas. As primeiras indicam o que ocorre em cena, se é dia ou noite, se a cena é interna ou externa, e traz indicações para a composição do cenário. Também é chamada de vista e fica no centro da página, na parte superior de cada cena, escrita em itálico ou em letra maiúscula. A microrrubrica é mais específica, encontra-se no corpo do texto e afeta a ação cênica; são divididas em objetivas e subjetivas. As microrrubricas objetivas se referem à movimentação dos atores e as subjetivas indicam estados emocionais dos personagens, bem como o tom das falas (COBRA, 2009).

${ }^{8} \mathrm{O}$ grupo, antes de iniciar a escrita da peça, assistiu a uma peça de teatro, no teatro da UBRO, em Florianópolis. Isso aconteceu no final de semana. 
capítulos do romance Goosebumps: ele saiu debaixo da pia foram divididos entre os sujeitos para que eles realizassem a reenunciação do gênero romance para o gênero peça de teatro. Essa primeira parte de escrita foi centrada nos seguintes aspectos: indicação dos personagens no canto esquerdo da página e marcação das microrubricas.

* 19a a $21^{a}$ sessões: escrita da peça (parte 2): após união dos capítulos $^{9}$ do romance reenunciados para a peça de teatro, o grupo procedeu à divisão da peça em cenas (pautada na entrada e saída de personagens) do texto produzido pelo grupo. Também realizaram a marcação das macrorubricas.

$22^{a}$ a $25^{a}$ sessões $^{10}$ : após o processo de escrita foi realizada a revisão da peça inteira produzida pelo grupo. Cada integrante revisou inclusive a parte escrita pelos colegas.

$\mathrm{Na}$ sequência, apresentamos o primeiro texto completo produzido por M (em sessão individual) referente à reenunciação do capítulo quatro do romance lido.

\section{$3 \mathrm{O}$ processo de escrita de $\mathbf{M}^{11}$}

[12/03/2009] Produção textual de M.

${ }^{9}$ A terapeuta digitou, preservando a escritura dos sujeitos, todas as produções individuais, unindo-as em uma peça completa. Entregou uma cópia para cada participante do grupo para o seguimento do procedimento terapêutico.

${ }^{10}$ As demais sessões, 46 ao todo, foram destinadas aos ensaios, encenação e também ao trabalho com os gêneros sinopse e cartaz de divulgação.

${ }^{11}$ Referente à $12^{\mathrm{a}}$ sessão terapêutica; $\mathrm{M}$ já havia, portanto, realizado onze sessões de terapia fonoaudiológica. 
(1)Cena 1

(2)DANIEL - AAAAIIII!

(3)KAT - Meu Deus Daniel, deu para ouvir seu grito a vários quarteirões daqui.

(4)Cena 2

(5)[A mãe ouve o grito e ven correndo]

(6)MÃE - O que acomtecel? Quem gritol? O que ouve? O que está acomtecendo? (7)DANIEL (sai de baixo da pia segurando a cabeça) - Bati a cabeça na pia (fala

(8)choramingando). Kat me empurrol.

(9)MÃE - Coitadinho. (abraça Daniel).

(10)KAT - Eu não enpurrei, eu nem pus a mão nele.

(11)DANIEL (gemendo) - Pucha como dói, Acho que vou ficar com um galo

(12)enorme aqui. Você fez de propósito Kat. E a esponja nem é sua ela estava na

(13)casa. Isso quer dizer que ela é de todo mundo.

(14)KAT - A esponja é minha, qual é o seu problema Daniel? Porque você sempre (15)quer o que é meu?

(16)MÃE - Chega, Não acredito que vocês estão brigrando por causa de uma

(17)espomja imprestável. Kat não era para você estar cuidando do seu irmão? (vira

(18) para Kat). E você, Daniel não pegue o que não é seu.

(19)MÃE - (Virou e sail da cozinha) Não quero ouvir mais nenhuma palavra sobre (20)essa bendita esponja. Ou vocês dois vão se arrempende.

(21)DANIEL - (Daniel mostra a língua para Kat e revira os olhos).Obrigado pela (22)confusão que você me metel. / sai da cozinha.

(23)KAT - todo mundo está gritando e berrando por aqui (sussurra para a esponja) (24)Você não acha que está trasendo muinta confusão? Você está viva?

(25)KAT - (pega a esponja na mão e ela está pulsando). Eu estol ouvindo as batidas (26)de um coração? Puxa! (grita espantada) Eca! (geme estremecendo). Pai Pai

(27) (corre para sala de visitas)

(28)[o pai de Kat está encima de uma escada e com a boca cheia de pregos]

(29)PAI - O que kat presizo instalar esta lâmpada no corredor.

(30)KAT - Tome, Pai (mostra a esponja) de uma olhada nisso.

(31)PAI - Deixe eu ver (se abaixa para pegar a criatura, quando cai da escada).

(32)Nãããoooo.

(33)[O pai cai no chão e o lustre cai na sua cabeça]

(34)KAT - Mãe, socorro! (grita desezperada). 
Abaixo, explicitamos excertos da interlocução que gerou a produção textual acima.

(1) $[12 / 03 / 2009]$

$\mathbf{M}:$ Tem que por primeiro cena 1 , aí começa.

$\mathbf{T}^{12}$ : Pode ser, se bem que acho que a gente vai ter que fazer essa parte de separar em cenas depois. Juntamos tudo e separamos em cenas. Mas se você quiser ir colocando... coloca...

M: Mas como é que a gente vai fazer sem as cenas? Não ensaia uma cena, depois outra cena...

T: É... será que não é melhor separar em cenas de uma vez?

M: Melhor...

T: Mas sabe que que é, é que depois, é que às vezes começa um capítulo... é que fica mais organizado... porque às vezes começa um capítulo e está no meio de uma cena, sabe, aí você tem que voltar no capítulo de outro colega...

M: Tem que ficar lendo pra frente e pra trás?

T: Exatamente. Não coincide. Só se todo mundo fizesse tudo junto, aí dava... mas aí vai uma eternidade.

M: Então vou por cena... as cenas... mas do meu capítulo, não vou ficar lendo o capítulo dos outros não, tá?

T: Acho ótimo.

Podemos observar, pelo episódio acima, que M já traz consigo aspectos relacionados às condições de produção de seu texto ${ }^{13}$. Não foi necessário realizarmos qualquer comentário a esse respeito no momento do nosso diálogo. O fato de ele dizer como é que a gente vai fazer sem as cenas? Não ensaia uma cena, depois outra cena?, significa que ele estava intentando produzir uma peça efetivamente. O que M diz manifesta a consciência que possui quanto aos interlocutores envolvidos nesse processo.

${ }^{12} \mathrm{~A}$ pesquisadora recebeu o $\mathrm{T}$ devido à sua condição de terapeuta.

${ }^{13}$ Importante comentar que a noção de texto que adotamos é aquela de Bakhtin (2003), ou seja, do texto visto na qualidade de enunciado, que se manifesta na interação verbal, mantendo, portanto, relações dialógicas com outros textos, anteriores e posteriores a ele. 
É verdade que, em sessões anteriores, já havíamos comentado o porquê de a peça ter de ser escrita com uma determinada configuração, pois se tratava de uma escrita contendo orientações para o trabalho teatral das pessoas relacionadas com a apresentação do espetáculo. Não informamos intencionalmente aos sujeitos que se ensaiava uma cena, depois outra. Isso mostra que $\mathrm{M}$, além de ter estado atento a todo o processo de trabalho com o gênero peça de teatro, estava levantando suas próprias hipóteses e demonstrando-as no momento da interação. Hipóteses essas que fazem com que reflitamos sobre nossa própria posição de terapeuta: será que não é melhor separar em cenas de uma vez? Tal consideração é um indício de que, na atividade dialógica, ambos os sujeitos se afetam (no nosso caso, sujeito/paciente e terapeuta); o que um faz e diz repercute no que o outro faz e diz; tem-se, desse modo, uma relação intersubjetiva eficaz, algo, aliás, também já constatado nas investigações de Abaurre (2006).

Percebemos ainda que, no jogo de negociações entre os parceiros do discurso, $\mathrm{M}$ demonstrou insatisfação em ter de voltar e possivelmente ler o capítulo de outro colega, caso já quisesse ir dividindo seu texto em cenas: tem que ficar lendo pra frente e pra trás? Por isso, chegou à conclusão que iria, de fato, dividir sua peça em cenas, mas apenas as cenas relacionadas a seu capítulo, algo a que não nos opusemos; ao contrário, incentivamos $\mathrm{M}$ a ter suas próprias opiniões, ou seja, a não ficar na dependência exclusiva do que lhe era dito.

Dando prosseguimento ao processo de produção conjunta entre sujeito da terapia e terapeuta, continuamos a apresentar trechos da interação estabelecida com M:

(02) $[12 / 03 / 2009]$

M: (escreve Daniel saiu, apaga e coloca sai). O Daniel sai (enfatiza) debaixo da pia, né?

T: Por que sai? Por que Daniel sai debaixo da pia?

M: Porque é que que o Daniel tá no palco daí ele sai.. sai debaixo da pia lá no palco na hora da peça..

T: Tá. E no livro o Daniel também não sai debaixo da pia?

M: (pensa). Não, tô falando que no livro tá escrito, aqui oh.. no livro tá escrito que saiu, que Daniel saiu debaixo da pia. A mulher tá contando que o Daniel saiu, aqui [mostra seu texto] é sai porque no palco ele sai... 
M, demonstrando seu processo de aprendizagem, em alguns momentos, no decorrer da escrita da peça, ainda nessa fase inicial, colocou alguns verbos das indicações no tempo pretérito. Acreditamos que uma das formas que o terapeuta da linguagem escrita pode dispor para compreender o percurso desenvolvido pelo sujeito/paciente, seja o de observar as pistas que o sujeito deixa no seu texto, como os apagamentos, substituições, deslocamentos etc. Segundo Abaurre (2006), essas pistas colaboram para o entendimento das hipóteses que o sujeito está formulando em dado momento específico de sua ação de aprender. Assim, observar M colocando um verbo no pretérito, depois apagando e colocando no presente, ou mesmo não apagando e seguindo em diante, fornece-nos subsídios para agir exatamente no ponto em que o sujeito precisa. Como diz Bakhtin (2003), é pelo texto que o homem fala, exprime-se em toda a sua especificidade humana. Em clínica, os textos de nossos sujeitos/pacientes nos dizem o que eles necessitam, e por onde devemos agir, considerando as suas reais necessidades. De maneira análoga, com o trabalho centrado na apropriação de determinado gênero, a observação das hipóteses de nossos sujeitos sobre o processo da sua escritura, sobre que conhecimentos possuem e de quais necessitam com relação ao gênero trabalhado, permite que se aja de forma efetiva para a sua aprendizagem e desenvolvimento (do sujeito), pelo e no processo da vivência terapêutica. O caso de $\mathrm{M}$ exemplifica esse processo, pois, quando levado à releitura de seu próprio texto, em determinados momentos, procedia, ele mesmo, à adequação dos tempos verbais conforme a escrita de uma peça exigia.

Com relação aos aspectos ortográficos, observamos que $\mathrm{M}$ apresentava instabilidades quanto à marcação do $u$ e $l$ no final de palavras. Podemos observar em sua produção escrita várias ocorrências, como por exemplo, empurrol, sail, metel, gritol. Percebemos que suas hipóteses para estas produções demonstravam que ele já se dava conta de que a escrita não era uma transcrição da oralidade, na medida que na variante falada por $\mathrm{M}$ o $l$ em final de sílaba é pronunciado como $u$ (vocalizado), e mesmo com essa pronúncia de $u$, ele grafava, algumas vezes, com $l$. Vimos, então, a necessidade de provocar em M algumas questões para que refletisse: 
(03) $[12 / 03 / 2009]$

T: [...] Mais uma coisa M: eu queria que você percebesse uma coisa...aqui oh você escreveu empurrou com 1 , aqui... você escreveu saiu com 1 e aqui meteu com 1 .. acho legal porque você já percebe que a fala e a escrita tem algumas diferenças... senão sempre que tivesse som de u na fala você botaria u, né? Tá, então.. como você já viu palavras escritas com 1 tipo sol, farol, que a gente fala com u e põe 1, então na hora você fica em dúvida que letra colocar.

M: (cara de interrogação) sim, sim (diz baixinho). Tu já disse já...

T: Claro que com a leitura essas coisas todas vão se resolvendo, você vai lendo, lendo e depois de ler "saiu", com u, depois de ler "saiu" várias vezes com u, tranquilo, você vai saber que é com u e pronto.. Mas.. agora.. mesmo sem ter muita leitura dá pra perceber alguma coisa.. Olha, vamos ver juntos, vê bem, sol, farol, caracol.. qual mais que termina com ó?

M: Deixa eu ver.. peraí.. (pensa).. não sei não..

T: Parece..percebe.. parece que no final da palavra quando termina assim aberto, com ó, tem a tendência de escrever com 1.. ai, queria mais exemplo.. e quando é som mais fechado tipo saiu, meteu, aconteceu, morreu, som mais fechado, é $\operatorname{com} \mathrm{u}^{14}$.

M: Escorregou..

T: É M, escorregou com u, se fosse escorregou (diz escorregóu) era.. tinha chance maior de ser com 1.. Ah, gelol!! Caiu, escorregou, gelol, geló, termina com 1 .

M: Tu já falou já, mas eu esqueci..

${ }^{14} \mathrm{Na}$ seção do dia 21/5/2009, quando os sujeitos, em situação de terapia em grupo, operavam na revisão da peça produzida, a questão da marcação do 'u' e 'l' em final de palavra foi novamente retomada. Na ocasião, M acabou por nomear uma suposta regra para esse uso: "a regra do sol" e a explicou para os colegas. Aproveitamos a oportunidade para estabelecermos uma exceção para "nossa regra", que se relacionava às palavras acentuadas, como no vocábulo 'céu', por exemplo. Em clínica, determinadas situações favorecem a busca conjunta de algumas regularidades para a ortografia da Língua. 
T: Não é esquecer.. é assim mesmo.. a gente tá vendo tanta coisa.. não dá pra lembrar de tudo, aos pouquinhos, depois, principalmente lendo, você vai pegando.. mas é só pra você pensar um pouco sobre isso...

M: Mas eu não penso muito assim, eu acho que é a letra e boto a letra e escrevo... não fico pensando nisso..

T: Cê acha que é com l e daí não tem dúvida se é com l ou se é com u?

M: É. Vou lá e boto.. não fico pensando.. mas às vezes eu acho que eu penso, já não sei mais se eu penso, mas acho que eu não penso..

T: É que às vezes a gente tá tão concentrado naquilo, no conteúdo, sabe, que esquece mesmo.. mas tem que pensar que às vezes escrever de um jeito, com outra letra pode até mudar a palavra, assim, carro e caro, por exemplo, muda tudo.. Aí se muda fica mais difícil pra pessoa entender o que tá escrito.. .Ela tem que voltar no texto, lê de novo pra ver se entende.. Mas, vem com o tempo.. .mas pra publicar o texto tem que seguir a norma..

M: Tá.

T: Pra falar cada um fala de um jeito, normal.. quem é do norte fala diferente do povo do sul, quem tem muito estudo pode falar diferente de quem não tem estudo nenhum, normal.. mas pra escrever tem uma norma, pra todo mundo se entender tem que obedecer essa norma.. Por exemplo, tá na norma que carro se escreve com dois erres.. que japonesa tem som de $z$, mas escreve com s.. essas coisas..

[silêncio]

T: Tenta dar uma olhada no livro na hora da adaptação.. Outra coisa: se eu tenho dúvida eu vou lá e escrevo de todos os jeitos possíveis.. então..meteu é com u ou com l? Aí escrevo [escreve meteu/metel], qual você acha que é?

M: Agora já sei, né.. (aponta para meteu)

T: É que a gente tem um tipo de memória que guarda a forma que as palavras são escritas... aí depois de ler bastante.. a tendência é escrever de acordo com a tal da norma.. mas pensando que seus colegas vão ler o seu texto.. então, 
pensando no caso da memória, seus colegas vão ler pra ensaiar.. vão ter que ler várias vezes.. aí imagina, se eles guardam meteu com 1. . Ou, imagina eles com dificuldade de entender o que você escreveu.. Pensa uma coisa: eles, seus colegas, estão aprendendo com você, lendo as coisas que você está escrevendo pra eles..

Sobre o episódio acima, existem algumas considerações que não podemos deixar de realizar. Uma delas se relaciona ao fato de como lidamos com as questões ortográficas no que diz respeito ao trabalho centrado na linguagem escrita. Grande parte das crianças/ adolescentes que são encaminhados para atendimento na área da leitura e da escrita tem uma concepção estabelecida que escrever bem é escrever corretamente do ponto de vista ortográfico. Muitos de nossos sujeitos produzem bons textos, porém, quando vão se dirigir a nós para entregá-los, antecipam o que consideram nossa reação-resposta: já sei, tá tudo errado. E ao questionarmos a compreensão que eles têm sobre o que é o errado, referem-se exclusivamente a aspectos da inadequação das suas grafias à língua padrão.

Em terapia, temos de redimensionar o status que as questões ortográficas recebem ${ }^{15}$. Sabemos que a atitude dos sujeitos retrata a sua vivência no ensino formal recebido na escola. Desse modo, somos, em clínica, motivados a dar novos sentidos à relação dos sujeitos na aprendizagem das questões ortográficas. Esse novo sentido passa, em primeiro lugar, pela noção posta de que a preocupação central do terapeuta está no que é dito pelo sujeito e nas estratégias ${ }^{16}$ usadas por ele para dizer. Assim, a ortografia é trabalhada no discurso, enquanto estratégia do dizer, já que a ortografia pode comprometer, em alguns casos, os sentidos produzidos no discurso.

${ }^{15}$ Esse redimensionamento passa pela noção de que a relevância dos aspectos ortográficos está no favorecimento da percepção dos sentidos veiculados pelo discurso. O sujeito tem de saber que o que ele diz e a forma como diz, pode possibilitar/favorecer a compreensão da sua locução/do seu enunciado. 16 “Estratégias de dizer" é uma expressão cunhada por Geraldi (1997). 
Ao dizermos para M, como está exposto no episódio acima, vocêjá percebe que a fala e a escrita tem algumas diferenças, estávamos mostrando a ele o quanto já havia refletido sobre a escrita ao perceber que esta apresenta diferenças se comparada com a oralidade. Ao dizermos ao sujeito/paciente que ele já reflete sobre as diferenças entre escrita e oralidade, estamos ao mesmo tempo dizendo a ele que existem diferenças entre a escrita e a oralidade, estamos explicitando uma reflexão que $\mathrm{M}$ já fazia, só que até então de modo não consciente. Também ao dizer posteriormente claro que com a leitura estas coisas vão se resolvendo, objetivamos mostrar que a leitura é enriquecedora também nesse sentido, já que possuímos uma memória visual que armazena grafias de palavras.

Desse modo, ao pedirmos a M tenta dar uma olhada no livro, oferecemos uma estratégia que poderia favorecer a escrita adequada do ponto de vista ortográfico, já que para realizar a adaptação do livro, era necessária a leitura do livro. Também sugerimos que, justamente recorrendo à memória lexical, $\mathrm{M}$, quando estivesse com dúvida quanto à grafia, escrevesse a palavra com suas formas possíveis; pois visualizando as formas, tendemos a optar por aquela que nos pareça mais familiar. Ainda, relembrando o papel do interlocutor imediato na produção de $\mathrm{M}$, alertamo-lo para o fato de que seus colegas leriam seu texto e o leriam várias vezes a fim de ensaiar para a encenação e que, em decorrência da memória lexical que possuímos, eles deveriam "memorizar" as palavras com a grafia correta. E, principalmente, buscando estabelecer o sentido de trazer as questões ortográficas para discussão, intentamos fazer com que $M$ percebesse que, quando se escreve para alguém, esse alguém necessita compreender o dito e a ortografia entraria como elemento favorecedor desse entendimento. Por isso, ao dizermos imagina, eles [colegas de grupo] com dificuldades de entender o que você escreveu, quisemos, em meio a um contexto significativo de produção de linguagem, resgatar a interação autor/leitor como forma de reflexão sobre a proposta de escrita.

O fato de tocarmos nessas questões deixou M com dúvida em relação ao seu próprio processo de conscientização: É. Vou lá e boto [a letra], não fico pensando... mas às vezes eu acho que eu penso, já não sei mais se eu penso, mas acho que eu não penso... Isso reforça o que havíamos dito anteriormente, de que há um conhecimento nem sempre consciente 
por parte do sujeito. O simples fato de escrever metel já denota que M sabe que a escrita não é a transcrição da fala, como mencionamos anteriormente. No entanto, não se dá conta disso, e ao chamarmos a atenção para o seu ato, fizemos com que pensasse sobre o seu próprio pensar e agir. Nossa intenção, ao trabalhar com a linguagem escrita, é a de propor ações que provoquem no sujeito a consciência do seu processo de aprendizagem, que gerem um estado de transformação pela atenção à forma de se conhecer o objeto escrita e de sobre ele atuar. Mediar é, portanto, tornar o sujeito consciente e afeto com relação ao seu processo de aprendizagem, fato pouco observado nas situações de ensino em esfera escolar. Bortolotto (2001) afirma que o ato pedagógico, como ato social, pode, em determinadas circunstâncias em que só uma consciência está em jogo (a do professor), deixar de ser direcionado para o sentido do agir humano:

Escolariza-se o ato (como fazer) em nome de uma pedagogia que incorpora uma organização requerendo conteúdos delimitados para um ensino que transmite conceitos 'definitivos' explicados como verdades já abstraídas de sua historicidade. A situação de interação é, pois, polarizada: a direção do processo é determinada pelo professor praticamente como elemento único do discurso (função autoritária, sem contrapalavra). Nessa 'pequena temporalidade' das situações interativas em sala de aula, o que determina o acabamento é o conteúdo fixado e não discutido. (BORTOLOTTO, 2001, p. 118)

Bakhtin (2003, p. 316 - grifo do autor) diz que "na explicaşão existe apenas uma consciência, um sujeito; na compreensão, duas consciências, dois sujeitos [...]. Em certa medida a compreensão é sempre dialógica". Tornar o sujeito da terapia consciente do seu processo de aprendizagem é agir dialogicamente, é propiciar um ambiente em que duas consciências agem: a do sujeito/paciente e do terapeuta. É, ao mesmo tempo, ressignificar possíveis vivências estabelecidas na escola, em que o aluno é concebido como um ser que deve absorver prontamente e mecanicamente tudo o que lhe é transmitido. 
Para Bakhtin (2006, p. 111 - grifo nosso), a língua não pode ser transmitida, porque ela "dura e perdura" sob um contínuo processo de evolução. "Os indivíduos não recebem a língua pronta para ser usada; eles penetram na corrente da comunicação verbal; ou melhor, somente quando mergulham nessa corrente é que sua consciência desperta e começa a operar." Desse modo, somente no fluxo do discurso é que o sujeito pode percorrer um caminho de apropriação consciente da língua escrita, em todas as suas dimensões, pois ao operar com e sobre a linguagem (GERALDI, 1997), ao refletir com e sobre a linguagem, estará ampliando seus conhecimentos acerca da leitura e escrita. Propiciar ao sujeito o entendimento de que a forma só tem relevância na medida em que materializada o discurso, e que este sim é que carrega o sentido do dito, funciona, em certo ponto, como um mecanismo de quebra do status das questões ortográficas. Assim, é possível fazer com que sujeitos percebam que o que escrevem não está tudo errado (como costumam relatar), mas que sua escrita pode necessitar de adequações (formais e/ou discursivas) para favorecer o sentido do que é escrito.

Continuemos a esmiuçar um pouco mais a interação estabelecida na produção da parte inicial do roteiro de M:

(04) $[12 / 03 / 2009]$

(Continua escrevendo, coloca toda a indicação da movimentação do personagem no passado - 25 e 26).

T: M, você colocou toda essa parte no passado... Você lembra porque no roteiro, nas indicações, os verbos vão no presente?

M: Que droga! Eu sabia e agora esqueci.

T: Normal. [...] É assim, oh, [...] Como o espetáculo acontece no momento que o público tá ali assistindo, os verbos das ações ${ }^{17}$ vão no presente. Não se conta uma história que já passou, como nos livros, se conta uma história que tá passando. Se tá acontecendo é presente: Kat VAI para a cozinha; Daniel CORRE pelo quintal... Entende?

$[\ldots]$

M: É...

${ }^{17}$ As ações a que nos referimos são as indicações de cena. 
T: Eu peguei a esponja e ela estava pulsando? Eu estava ouvindo as batidas de um coração? Puxa, gritei espantada?

M: Não. Eu sei... (apaga e escreve colocando os verbos no presente)

M: Na hora como é que o público vai ouvir o coração da esponja bater?

T: Boa pergunta... Não vão ouvir... Ah, se bem que no teatro dá pra por o som que quiser...

M: Quem não quiser apresentar vai ficar lá atrás fazendo os barulho (risos).

T: Você sabia que tem gente que faz isso mesmo?

M: Eu sei.

T: Tá M, ah, então, mas acho que na batida do coração só a Kat falando, fazendo que tá ouvindo, já dá pro povo ver... Você tem que por na fala dela... O povo que tá vendo tem que sentir o coração do grool bater...

M: (olha pro texto e diz baixinho) pega a esponja e ela está pulsando... Ela vai ter que ficar mexendo a mão... Posso colocar meu celular vibrando dentro da esponja, aí a esponja vai mexer...

Nesse diálogo representativo, novamente podem ser observados aspectos do processo da aprendizagem dos sujeitos. O enunciado de M sabia e esqueci em resposta ao dito que o alertava de ter marcado os verbos no pretérito, é um indicativo de que a aquisição de determinados gêneros do discurso nem sempre é fácil, há gêneros pouco conhecidos - caso das peças de teatro - que requerem ensino intencional e mais tempo de aprendizagem, um constante ir e vir; demandam explicações, repetições da explicação, até que o sujeito adquira autonomia enunciativa.

Também, mais uma vez, percebemos a imagem do interlocutor presente no momento do processo da escrita de $\mathrm{M}$ e que, de certa forma, "modela" a produção do seu discurso: na hora como o público vai ouvir o coração da esponja bater?. Podemos observar como o sujeito estava atento às possíveis percepções do público em relação àquilo que seria encenado - dito pela escrita - e que seria possível representar. A preocupação era tanta, que $\mathrm{M}$ inclusive pensou em uma saída para o suposto problema, que foi o de colocar seu celular vibrando dentro 
da esponja. O auditório social acompanhou todo o tempo a situação comunicativa em que $\mathrm{M}$ se assumia como escritor/autor. Bakhtin (2006[1929], p.129) diz que "a enunciação realizada é como uma ilha emergindo de um oceano sem limites, o discurso interior. As dimensões e as formas dessa ilha são determinadas pela situação de enunciação e por seu auditório. A situação e o auditório obrigam o discurso interior a realizar-se em uma expressão exterior definida [...]". Trabalhar na perspectiva teórica de Bakhtin (2003) quanto aos gêneros do discurso pressupõe sempre considerar as relações interlocutivas estabelecidas no processo de produção de linguagem: o outro está sempre no horizonte do enunciado do locutor.

Após a produção deste texto, M. seguiu em processo terapêutico, recebendo alta dez meses depois. Em uma das sessões finais, revelou que havia chegado a hora de "levar a sério", referindo-se ao seu maior comprometimento com os estudos. Antes da alta, produziu um texto dirigido para os próximos participantes do trabalho com o gênero peça de teatro. Nesse texto, $\mathrm{M}$ escreveu, em relato sobre sua experiência, que havia perdido um pouco da sua timidez, e acrescentou: gostei muito de ler o livro e ver o teatro e depois que eu comecei a vir aqui as minhas notas na escola aumentaram.

\section{Considerações finais}

O mais importante ao fim deste trabalho é refletirmos sobre o sujeito da clínica/sujeito da escola, aquele que se constitui pela linguagem [e que se apropria da linguagem] na relação com o outro. É em uma atmosfera heterogênea, inserido em uma realidade de múltiplas relações, que o sujeito vai se constituindo discursivamente, apreendendo diversas vozes sociais. "É nesse sentido que Bakhtin várias vezes diz, figurativamente, que não tomamos nossas palavras do dicionário, mas dos lábios dos outros" (FARACO, 2009, p. 84).

Sobre a questão da subjetividade nos processos de letramento escolar, Pan (2006, p. 88) pergunta: como tem sido analisado o discurso da escola sobre o aluno? Como a subjetividade é produzida nesse universo de relações onde estão representados os "bons alunos", os "maus alunos", os "hiperativos", "os disléxicos"? Segundo a autora, "a instituição escolar e o discurso pedagógico atualizam as interpretações sobre a criança por meio de estratégias de normalização". 
Para o fonoaudiólogo, interessa compreender a história do sujeito relacional, constituída nas interações sociais pelos discursos que se engendram na vida social desse sujeito. Essa compreensão é necessária para que o fonoaudiólogo possa partir de uma proposta terapêutica pensada na ressignificação da queixa (atravessada por tais discursos). Nosso percurso analítico esteve centrado nas fronteiras entre esferas (BAKHTIN, 2003), a esfera da clínica e a esfera da escola, e é nessa fronteira que operamos na produção de novos sentidos para os sujeitos em suas relações com a linguagem e consigo mesmos. Pan (2006) considera que no caso das dificuldades dos sujeitos perante a apropriação da língua escrita, escola e especialistas se concentram em análises avaliativas (que se aproximam de uma crença vaga e universal) das produções de linguagem infantis. Os sujeitos/alunos/pacientes circunscritos nesses meios produzem discursos que materializam, ao mesmo tempo que denunciam, práticas educacionais que impõem uma homogeneização, massificação, e que se mostram avessos quando alguém se diferencia daquilo que é esperado. Nos termos de Pan (2006, p. 110),

A criança em si, incompreendida como devir, negada em sua condição de incompletude, ao aceder à linguagem da escola - a suposta linguagem una -sucumbe à verdade presente em seus discursos. A diferença deixa de ser da ordem da natureza das coisas humanas e passa à ordem do discurso, dos sentidos, do outro alfabeto com o qual a escola ensina a criança a ler e a escrever o mundo. Nesse alfabeto ela é o alvo principal. A partir de seus efeitos, a primeira lição introduz a mais central e subliminar das indagações: Quem somos nós e quem são os outros? A primeira diferença que começa a operar nesse universo de sentidos, em face da normalização da vida.

Temos como um compromisso ético o dever de construir novas possibilidades nas vivências mediadas pela língua escrita por sujeitos marcados pelo estigma das dificuldades de aprendizagem da leitura e escrita. Pensamos que nesse processo de ressignificar discursos e vivências, insere-se um trabalho voltado para o uso da língua em contextos significativos. Nesse ponto entramos com a teoria de gêneros 
de Bakhtin (2003). Ao trazermos o mundo da leitura e da escrita para o mundo da vida, atuamos na ressignificação do discurso da incapacidade linguística, por meio da (re)constituição de uma subjetividade permeada por outros discursos. Os sujeitos responsivos responderam à mediação do outro; mediação esta que acabou por interferir na imagem que o sujeito tinha de si. O sujeito $\mathrm{M}$ se engajou nas práticas sociais de leitura e escrita e, com isso, permitiu-se ser leitor e autor.

\section{Referências}

ABAURRE, M.B.M. Uma história individual. In: ; FIAD, R.S.F.; MAYRINK-SABINSON, M.L. Cenas de aquisição da escrita: o sujeito e o trabalho com o texto. Campinas: Mercado de Letras, 2006.

BAKHTIN, M. Estética da criação verbal. São Paulo: Martins Fontes, 2003.

. Marxismo e filosofia da linguagem. São Paulo: HUCITEC, 2006.

BERBERIAN, A.P. Linguagem escrita no contexto da clínica fonoaudiológica. In: LOPES FILHO, O. Tratado de Fonoaudiologia. São Paulo: Roca, 2006. p. 846-861.

BERBERIAN, A.P.; MASSI, G.A.M. A clínica fonoaudiológica voltada para os chamados distúrbios de leitura e escrita: uma abordagem constitutiva de linguagem. Revista da Sociedade Brasileira de Fonoandiologia, v. 1, n. 10, p. 43-52, 2005.

BERTHOLD, M. História mundial do teatro. São Paulo: Perspectiva, 2008.

BORTOLOT'TO, N. A interlocução na sala de aula. São Paulo: Martins Fontes, 2001.

COBRA, R.Q. Noções de teoria do teatro. 4 set. 2006. Disponível em: $<$ http://www.cobra.pages.nom.br/ecp-teatrotecnica.html>. Acesso em: 5 jan. 2009. 
FARACO, C.A. Linguagem e diálogo: as ideias linguísticas do Círculo de Bakhtin. São Paulo: Parábola, 2009.

GERALDI, W. Portos de passagem. São Paulo: Martins Fontes, 1997.

MASSI, G.A. A outra face da dislexia. 2004. Tese (Doutorado em Letras) - Universidade Federal do Paraná, Curitiba. 2004.

PAN, M. Letramento escolar e processos subjetivos. In: BERBERIAN, A.P.; MORI-DE ANGELIS, C.; MASSI, G.A. (Orgs.). Letramento: referências em educação e saúde. São Paulo: Plexus: 2006. p. 66-116.

PEIXOTO, F. O que é teatro. São Paulo: Brasiliense, 1981. (Coleção Primeiros Passos, 10). 